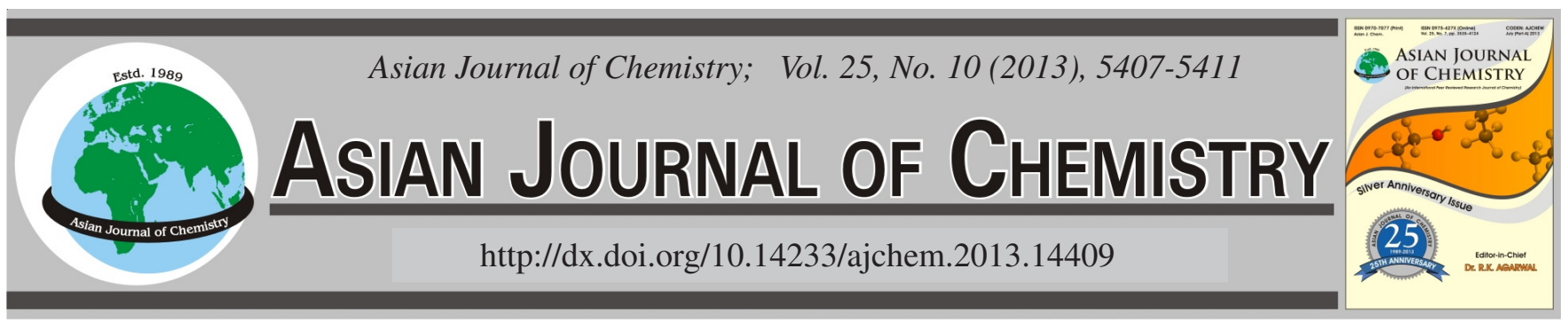

\title{
Application of Density and Viscometric Techniques in Estimation of Aggregation Behaviour of Polyethylene Oxide with Impact of Molecular Mass of the Polymer
}

\author{
Abdur Rauf ${ }^{1,2, *}$, Musa Kaleem Baloch ${ }^{1}$, Salma Rauf ${ }^{3}$, Malik Amanullah ${ }^{1}$, \\ Wajid Rehman ${ }^{4, *}$, Muhammad Adeel ${ }^{1}$ and Mohammad Akram ${ }^{5}$
}

\author{
${ }^{1}$ Department of Chemistry, Gomal University, Dera Ismail Khan, Pakistan \\ ${ }^{2}$ Department of Chemistry, Kings College London, UK \\ ${ }^{3}$ Department of Biological Sciences, Gomal University, Dera Ismail Khan, Pakistan \\ ${ }^{4}$ Department of Chemistry, Hazara University, Mansehra, Pakistan \\ ${ }^{5}$ PCSIR, Laboratories, Peshawar, KPK, Pakistan
}

*Corresponding authors: E-mail: rauf_afnan@yahoo.com; sono_waj@yahoo.com

(Received: 7 August 2012;

Accepted: 8 April 2013)

AJC-13217

\begin{abstract}
Polyethylene oxide having different molecular mass $(35,6,2 \mathrm{Kg} / \mathrm{mol})$ were studied by densitometry and viscometry in the temperature range of $20-50{ }^{\circ} \mathrm{C}$. Intrinsic viscosity $(\eta)$ and interparticle interaction parameter $\left(K_{H}\right)$ were determined at various temperatures from viscometry. Micellar partial specific volume $\left(v_{\text {mic }}\right)$ and micellar density $\left(\rho_{\text {mic }}\right)$ were determined by density measurement at various temperatures. Energy of activation $\left(\mathrm{E}_{\mathrm{a}}\right)$ was also calculated from intrinsic viscosity by using Arhenius equation. From the densitometric and viscometric results the amount of water in gram per gram associated with the aggregates of polymer (Wh) and shape factor of aggregate (micelle) were also determined. It was concluded that the intrinsic viscosity, micellar density and water associated with the polymer molecules were decreased as the temperature increased. While partial specific volume of polymer increased with the temperature.
\end{abstract}

Key Words: Density, Viscosity, Molecular mass, Polyethylene oxide.

\section{INTRODUCTION}

Polyethylene oxide (PEO), sometimes referred to as polyethylene glycol (PEG), is the most familiar of the above mentioned polymers. Its low toxicity and pseudo plastic properties produce unique benefits for all kinds of applications ${ }^{1} e . g$., it is used in contact-lens fluid; detergents and lotions, as adhesive, as thickener in acid cleaners and for drag reduction, foam stabilization, lubrication and oil-well flooding. At room temperature polyethylene oxide is miscible with water in all proportions. It is interesting to note that poly(methylene oxide) (PMO), which contains a larger portion of hydrophilic ether oxygen, is neither soluble in water and nor in poly(trimethylene oxide) (PTMO). It has been argued that the exceptionally good water solubility of polyethylene oxide stems from its conformation that allows a hydrating water molecule to bridge two ether linkages ${ }^{2-4}$. Upon heating, an aqueous polyethylene oxide solution eventually becomes hazy, i.e., it exhibits a lower critical solution temperature (LCST). The LCST is usually called cloud point or clouding temperature. At the cloud point a micro phase separation takes place in a polymer-rich phase and a waterrich phase. It is believed to arise from a breakdown of the protective hydration sheath of the polymer ${ }^{5,6}$ in pure water, the cloud point of a polyethylene oxide solution is near the boiling point of water. Addition of most salts lowers this temperature. Polyethylene oxide has gained popularity, especially in polymer-micelle research. The isomeric polymers PVME and PPO are much more hydrophobic than polyethylene oxide, though they are still soluble in water. For instance, PPO and PVME are also soluble in all kinds of organic solvents $\left.{ }^{7}\right]$ whereas polyethylene oxide is not. In contrast to PVME, the water solubility of PPO is limited to low molecular weight samples $(\mathrm{mw}<1500)$.

Florin et al. ${ }^{8}$ have concluded from a comparison of theoretical calculations and experimental viscosity data on PPO that this polymer (which is rather an oligomer) exists in aqueous solution as a tightly coiled disk with most of the hydrophobic methyl groups in the center of the coil. In a polar solvent like benzene the disk is uncoiled and a looser Gaussian coil configuration is formed. This uncoiling may also play a role in the binding of PPO chains on the micellar interface. Saeki et al. ${ }^{9}$ have compared the heats of mixing of PPO with water with those of polyethylene oxide and concluded that for both polymers hydrogen bonds between water and oxygen chain atoms are formed almost quantitatively ${ }^{6}$. Polymeric aggregates are shell like structure formed from the self assembly of amphiphiles 
in a solvent. In water these micelles are characterized by hydrophobic core shielded from external medium from hydrophilic shell. This particular type of aggregates has been studied extensively to improve aqueous solubility of hydrophobic therapeutic agents ${ }^{2}$.

The aggregation behaviour in aqueous solutions can be initiated at a given temperature by increasing the concentration beyond the critical aggregation concentration. In dilute solution spherical aggregates are formed while in concentrated solution, the spherical aggregates are oriented in super structure like body centered cubic, face centered cubic, hexagonal arrays of micelle and lamellar structure are formed ${ }^{3-6,8,9}$.

The present study has been undertaken to investigate in detail the association behaviour of poly(ethylene oxide) in aqueous solution using viscosity and density studies. The effect of temperature and molecular mass on various parameters, viz.; micellar density, partial specific volume, inter particle interaction parameters and number of water molecules attached with the single molecule have been monitored and explained.

\section{EXPERIMENTAL}

Density and viscosity measurements: Solutions of different concentration were prepared in water for densitometry and viscometric studies. Stock solution of polymer was prepared of $20 \mathrm{~g} / \mathrm{L}$. From this stock solution about fifteen other solutions were prepared by dilution method. Density and viscosity of dilute aqueous solution of polymers were determined in the temperature range of $20-50^{\circ} \mathrm{C}$, with the help of Stabinger Viscometer G2 ( SVM3000/G2 ) supplied by Anton Paar. SVM combines the accuracy of conventional capillary viscometers with the speed and ease of use of Anton Paar, s world leading digital density meters.

The instrument has different measuring modes; each has its own importance. We used M3 mode for our work, in which viscosity can be measured over wide range of temperature (with interval of $10^{\circ} \mathrm{C}$ ) for a single solution. The instrument has automatic temperature controlled system. First the sample cell ( $c a .3 \mathrm{~mL}$ ) was cleaned, washed, dried and then it was injected through the filling inlet with the help of disposable syringe and pressing the enter key of the instrument, it automatically start measuring viscosity and density over the given range of temperature. After $10 \mathrm{~min}$ the results were displayed on the instrument screen. After each measurement the sample cell were cleaned and dried with the air pump. In order to measure viscosity and density over a wide range of concentration, we diluted the stock solution and results were obtained by repeating the above procedure. The instrument directly gave the values of density, dynamic viscosity and kinematics viscosity.

\section{RESULTS AND DISCUSSION}

Density measurement of polyethylene oxide solution: Density of polyethylene oxide having molecular mass 2000 6000 and $35000 \mathrm{~g} / \mathrm{mol}$ were determined and plotted as a function of its concentration (Figs. 1-3). These figures show a little increase for density as the concentration of polyethylene oxide increases. The partial specific volume of the aggregates of polymer $\left(v_{\text {agg }}\right)$ were determined by relation given below from the solution density, [9f]

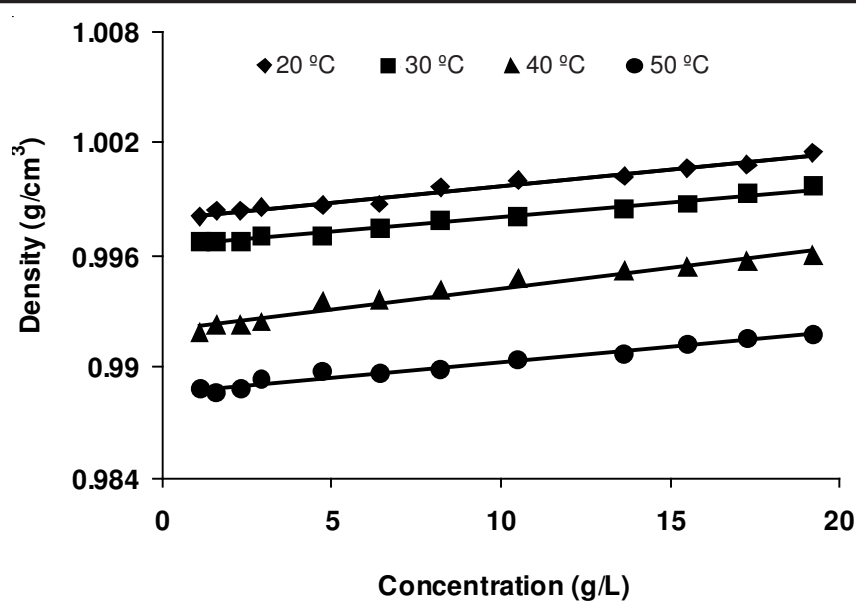

Fig. 1. Plot of solution density of polyethylene oxide verses temperature having molecular mass $2 \mathrm{~K}$ at different temperature

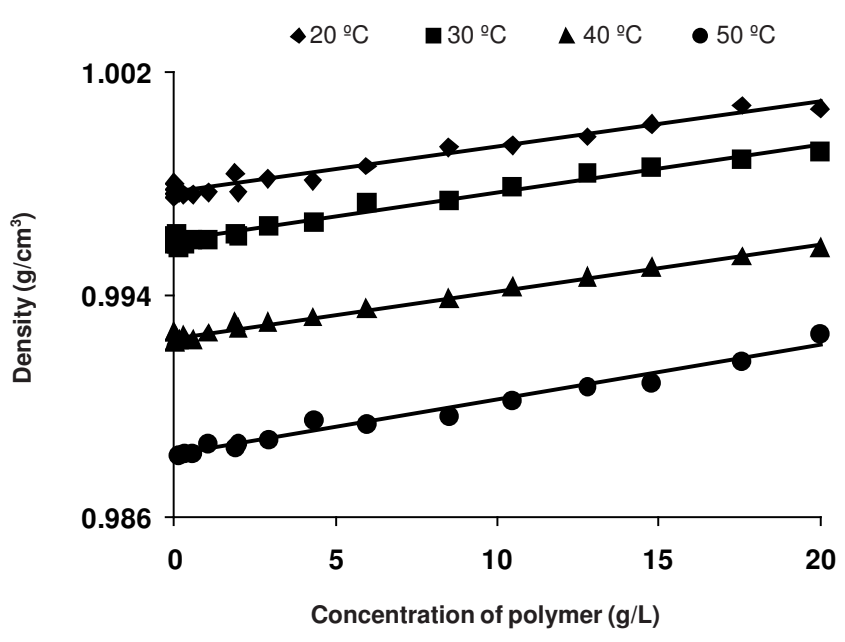

Fig. 2. Plot of solution density versus concentration of polyethylene oxide having molecular mass $6 \mathrm{~K}$ at different temperature

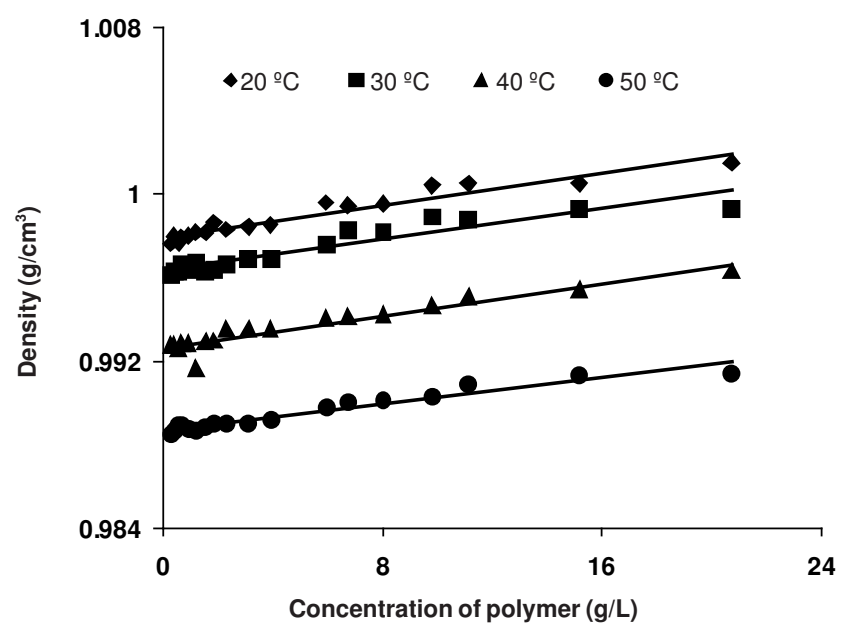

Fig. 3. Plot of solution density versus concentration of polyethylene oxide having molecular mass $35 \mathrm{~K}$ at different temperature

$$
\rho_{\text {soln }}=\rho_{\text {solv }}+\left(1+v_{\text {agg }} \rho_{\text {solv }}\right)\left(C_{\text {agg }}\right)
$$

Thus by plotting solution density of polymer versus its concentration (Figs. 1-3) the intercept gives solvent density $\left(\rho_{\text {solv }}\right)$ and from the slope partial specific volume of aggregates $\left(v_{\text {agg }}\right)$ of polymer were obtained. The inverse of the partial 


\begin{tabular}{ccccccc}
\hline \multicolumn{7}{c}{ TABLE-1 } \\
\hline $\mathrm{T}\left({ }^{\circ} \mathrm{C}\right)$ & $\rho_{\text {solv }}(\mathrm{g} / \mathrm{mL})$ & $\rho_{\text {(sol..) }}(\mathrm{g} / \mathrm{mL})$ & $v_{\text {agg }}(\mathrm{mL} / \mathrm{g})$ & {$[\eta](\mathrm{mL} / \mathrm{g})$} & $\mathrm{K}_{\mathrm{H}}(\mathrm{mL} / \mathrm{g})$ & $\mathrm{W}_{\mathrm{H}}(\mathrm{g} / \mathrm{g})$ \\
\hline 20 & 0.9974 & 0.9978 & 1.002205 & 1.15 & 0.0015 & -0.54 \\
30 & 0.9956 & 0.9963 & 1.003714 & 1.13 & 0.0038 & -0.54 \\
40 & 0.9923 & 0.9922 & 1.007861 & 1.10 & 0.0007 & -0.56 \\
50 & 0.987 & 0.9884 & 1.011736 & 1.08 & 0.0027 & -0.56 \\
\hline
\end{tabular}

TABLE-2

SYNOPSIS OF VISCOMETRIC AND DENSITOMETRIC RESULTS FOR POLY(ETHYLENE OXIDE) (6 K)

\begin{tabular}{ccccccc}
\hline $\mathrm{T}\left({ }^{(} \mathrm{C}\right)$ & $\rho_{\text {solv }}(\mathrm{g} / \mathrm{mL})$ & $\rho_{\text {(sol.. }}(\mathrm{g} / \mathrm{mL})$ & $v_{\text {agg }}(\mathrm{mL} / \mathrm{g})$ & {$[\eta](\mathrm{mL} / \mathrm{g})$} & $\mathrm{K}_{\mathrm{H}}(\mathrm{mL} / \mathrm{g})$ & - \\
\hline 20 & 0.9975 & 0.9977 & 1.002305 & - & - & $\mathrm{W}_{\mathrm{H}}(\mathrm{g} / \mathrm{g})$ \\
30 & 0.9957 & 0.9959 & 1.004117 & 1.24 & 0.0001 & - \\
40 & 0.99924 & 0.9925 & 1.007557 & 1.17 & 0.0002 & -0.50 \\
50 & 0.9888 & 0.9882 & 1.011941 & 1.03 & 0.0002 & -0.46 \\
\hline
\end{tabular}

TABLE-3

\begin{tabular}{ccccccc}
\multicolumn{7}{c}{ SYNOPSIS OF VISCOMETRIC AND DENSITOMETRIC RESULTS FOR POLY(ETHYLENE OXIDE) 35000} \\
\hline $\mathrm{T}\left({ }^{\circ} \mathrm{C}\right)$ & $\rho_{\text {solv }}(\mathrm{g} / \mathrm{mL})$ & $\rho_{\text {(soln. }}(\mathrm{g} / \mathrm{mL})$ & $v_{\mathrm{agg}}(\mathrm{mL} / \mathrm{g})$ & {$[\eta](\mathrm{mL} / \mathrm{g})$} & $\mathrm{K}_{\mathrm{H}}(\mathrm{mL} / \mathrm{g})$ & $\mathrm{W}_{\mathrm{H}}(\mathrm{g} / \mathrm{g})$ \\
\hline 20 & 0.9981 & 0.9979 & 1.00210 & 9.00 & 0.0020 & 2.60 \\
30 & 0.9959 & 0.9963 & 1.00370 & 9.11 & 0.0010 & 2.63 \\
40 & 0.9923 & 0.9926 & 1.00740 & 8.82 & 0.0009 & 2.51 \\
50 & 0.9884 & 0.9887 & 1.00114 & 8.35 & 0.0007 & 2.32 \\
\hline
\end{tabular}

specific volume gives density of aggregates $\left(\rho_{\mathrm{agg}}\right)$ of polymer. These results (Tables 1-3) show that there occur somewhat increase in the partial specific volume of the micelle with increasing temperature. The effect can be consigned to the enlargement of polymer chain by increasing the temperature. This is also supported by the corresponding decrease in micelle density $\left(\rho_{\text {mic }}\right)^{10}$.

Intrinsic viscosity and activation energy: Viscosity measurements were applied to determine the intrinsic viscosities and other valuable parameters which give helpful information about the hydrodynamic properties of the polymer micelle ${ }^{10}$. For that we first determined the dynamic viscosity of polymer poly(ethylene oxide) having molecular mass 35 and $6 \mathrm{~K}$ directly from the instrument and was converted to relative viscosity according to the following formulae.

$$
\text { Relative viscosity } \eta_{\mathrm{r}}=\frac{\eta_{\text {sol }}}{\eta_{\text {sov }}}
$$

The relative viscosity $\eta_{\mathrm{r}}$ was used to determine the specific viscosity and in turn reduce viscosity was also calculated by using relation (2) and (3), respectively.

$$
\begin{gathered}
\text { Specific viscosity } \eta_{s p}=\eta_{r}-1 \\
\text { Reduce viscosity } \eta_{\text {red }}=\eta_{r}-1 / \text { conc. }
\end{gathered}
$$

The intrinsic viscosity $[\eta]$ and interaction parameter $\left(\mathrm{K}_{\mathrm{H}}\right)$ for polymer at different temperature were obtained from graph as per using the Huggins relation given below ${ }^{11}$

$$
\frac{\eta_{\mathrm{sp}}}{\mathrm{C}}=[\eta]+\mathrm{KH}[\eta]^{2} \mathrm{C}
$$

Reduced viscosity $\left(\eta_{\mathrm{sp}} / \mathrm{C}\right)$ of polymer was plotted against its concentration (Figs. 4-6) and intrinsic viscosity [ $\eta$ ] was obtained from the intercept and $\mathrm{K}_{\mathrm{H}}$ from the slope.

When the solution concentration approaches zero, then the intrinsic viscosity is defined by the following formula ${ }^{12}$

$$
[\eta]=\lim C_{0}-\frac{\eta_{\mathrm{sp}}}{\mathrm{C}}=\lim \mathrm{C}-0 \ln \frac{\eta_{\mathrm{r}}}{\mathrm{C}}
$$

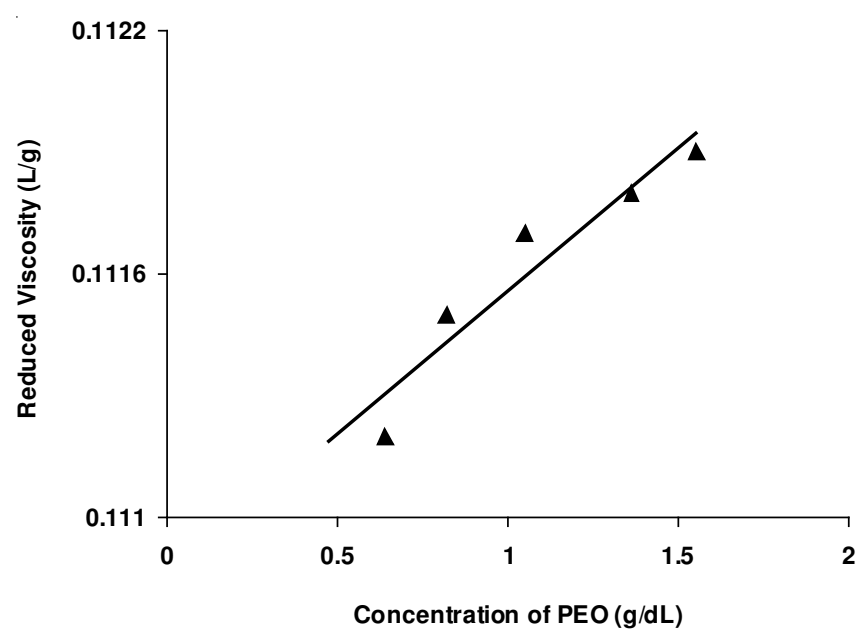

Fig. 4. Typical plot of reduced viscosity of polyethylene oxide $(2 \mathrm{~K})$ at $30^{\circ} \mathrm{C}$

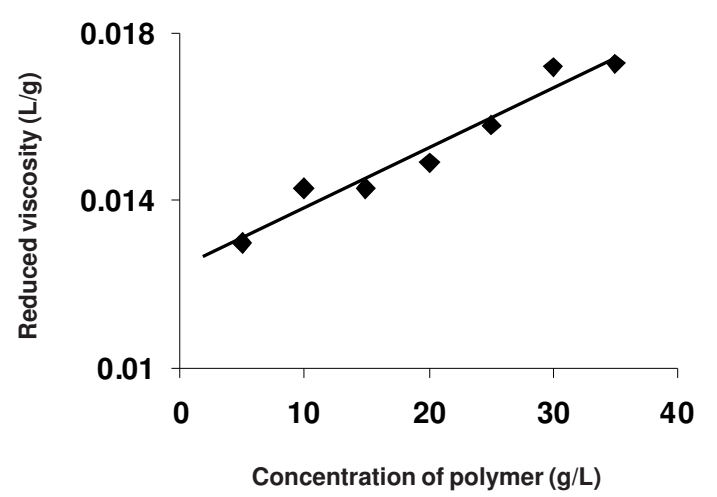

Fig. 5. Typical plot of reduced viscosity of polyethylene oxide $(6 \mathrm{~K})$ at $30{ }^{\circ} \mathrm{C}$

Tables 1-3 shows that values of intrinsic viscosities of polymer decrease with the temperature which is according to our expectation (Figs. 7-8). The values of interpartical interaction parameter are positive which indicate strong interaction 


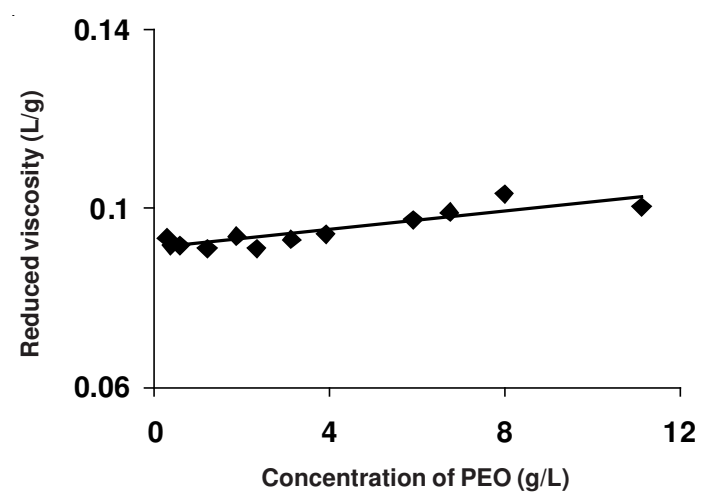

Fig. 6. Typical plot of reduced viscosity of polyethylene oxide $(35 \mathrm{~K})$ at $30{ }^{\circ} \mathrm{C}$

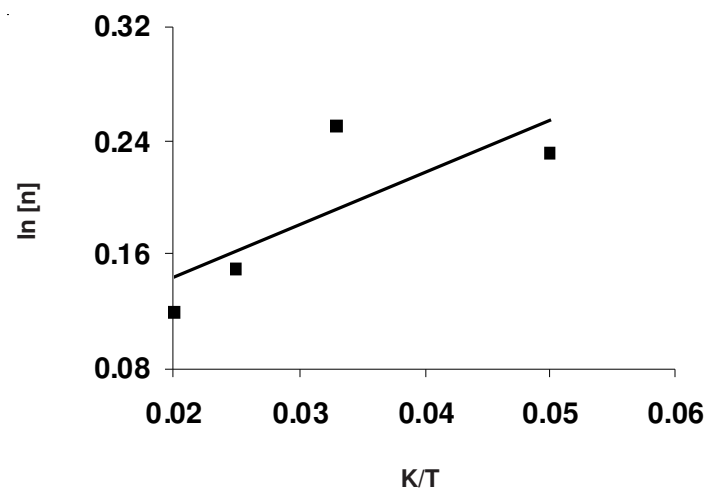

Fig. 7. Plot of $\ln [\mathrm{n}]$ as a function of $1 / \mathrm{T}\left(\mathrm{K}^{-1}\right)$ for polyethylene oxide $(6 \mathrm{~K})$

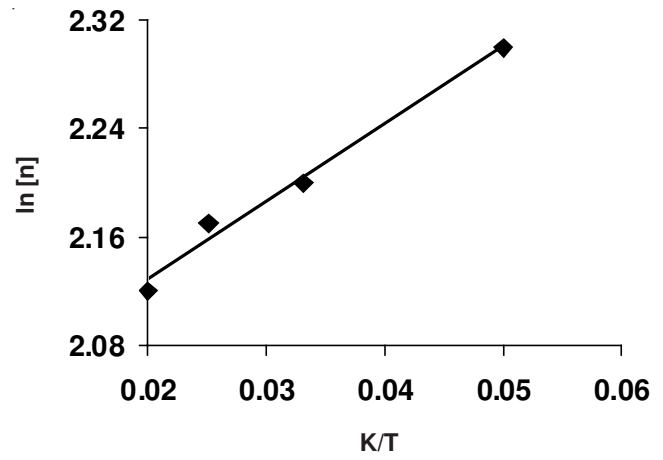

Fig. 8. Plot of $\ln [\mathrm{n}]$ as a function of $1 / \mathrm{T}\left(\mathrm{K}^{-1}\right)$ for polyethylene oxide $(35 \mathrm{~K})$

among the aggregation of polyethylene oxide ${ }^{11}$. This is due to hydrophilicity of poly(ethylene oxide). By rising temperature the interaction between the aggregations of polymer decreased i.e., $\mathrm{K}_{\mathrm{H}}$ value decreased as the temperature increased. This is due to the fact that increase in temperature decreases the solvent quality and hence interaction decreases.

By using intrinsic viscosity, solvent density and partial specific volume of polymer at a particular temperature, we have calculated hydration of aggregates of polymer, gram of water associated with the gm of polymer by applying the following relation ${ }^{13}$

$$
\mathrm{W}_{\mathrm{h}}=\frac{v \rho[\eta]}{(2.5 v-1)}
$$

The values of $\mathrm{W}_{\mathrm{h}}$ are given in table which shows that the values of $\mathrm{W}_{\mathrm{h}}$ in both cases decreases as the temperature increases with some experimental error. It means that at higher tempe- rature the aggregation of polymer increases and hence hydration decreases. However the value of hydration increases as the molecular weight of the polymer increases. Elaborating more contribution of $[\eta]$ to hydrodynamic properties of the micelle, we have also figure out the shape factor $(v)$ of micelle by using the values of $[\eta], W_{h}$ and partial specific $v$ by using the relation ${ }^{14}$

$$
v=\frac{[\eta]}{v^{\prime}}
$$

The values of shape factor $(v)$ of micelle indicate that the aggregates formed are of spherical nature ${ }^{14,15}$.

The energy of activation $\mathrm{E}_{\mathrm{a}}$ for both polymer having molecular mass 2, 35 and $6 \mathrm{~K}$ was calculated using Arhenius equation given below,

$$
[\eta]=\mathrm{A}^{\mathrm{E}_{\mathrm{a}} / \mathrm{RT}}
$$

Here $\mathrm{E}_{\mathrm{a}}$ is activation energy and $\mathrm{A}$ is pre-exponential constant or Arhennius constant a was calculated by plotting $\ln [\eta]$ versus $1 / \mathrm{T}$. These plots are shown in Figs. 7 and 8 . The activation energy calculated from the above graphs are plotted as a function of molecular mass in Fig. 9 and tabulated in Table-4, which shows that activation energy of polymer increases as its molecular mass increases ${ }^{16}$.

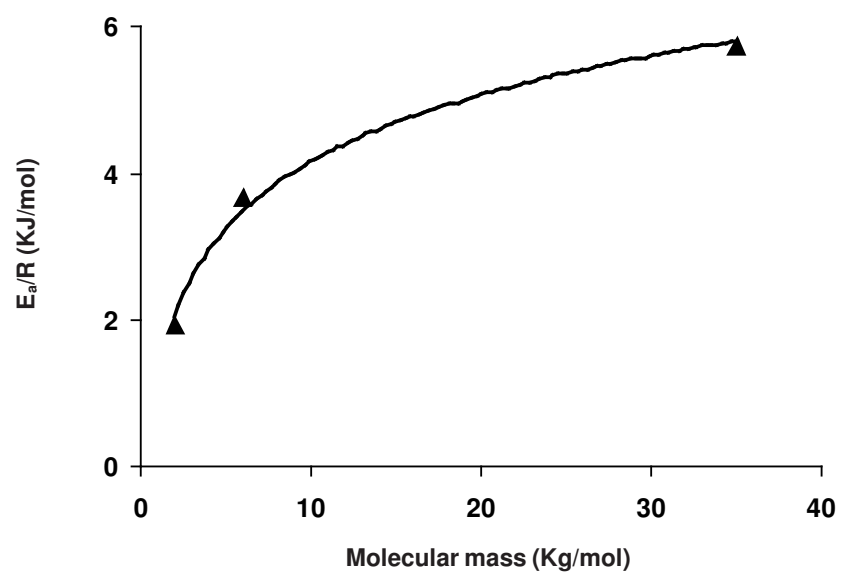

Fig. 9. Plot of activation energy as a function of different molecular masses for polyethylene oxide

TABLE-4

ACTIVATION ENERGY OF POLYETHYLENE OXIDE HAVING DIFFERENT MOLECULAR MASS $(2,6,35 \mathrm{Kg} / \mathrm{mol})$ Molecular mass $(\mathrm{Kg} / \mathrm{mol}) \quad \mathrm{Ea} / \mathrm{R}(\mathrm{KJ} / \mathrm{mol})$

$\begin{array}{ll}2 & 1.9340 \\ 6 & 3.6600\end{array}$

$35 \quad 5.7336$

\section{ACKNOWLEDGEMENTS}

One of the authors, Abdur Rauf is grateful to Higher Education Commission (H.E.C.) Pakistan for its financial support under IRSIP program and indigenous Ph.D fellowship scheme. The authors are also grateful to Dr. Musa Kaleem Baloch for the helpful advice. 


\section{REFERENCES}

1. A. Rauf, M.K. Baloch and G.F. Durani, J. Chem. Soc. Pak., 32, 32 (2010).

2. W. Luck, Fortschr. Chem. Forsch., 4, 653 (1964).

3. J. Breen, D. Huis, J. de Bleijser and J.C. leyte, J. Chem. Soc., Faraday Trans. I, 84, 293 (1988).

4. R. Kjellander and E. Florin, J. Chem. Soc., Faraday Trans., 77, 2053 (1981).

5. R.A. Horne, J.P. Almeida, A.F. Day and N.T. Yu, J. Colloid Polym. Sci., 35, 77 (1971).

6. M. Ataman, Colloid Polym. Sci., 265, 19 (1987).

7. S. Saeki, N. Kuwahara, M. Nakata and M. Kaneko, Polymer, 18, 1027 (1977).

8. E. Florin, R. Kjellander and J.C. Eriksson, J. Chem. Faraday Trans., 80, 2889 (1984).
9. M.M. Breuer and I.D. Robb, Chem. Ind. (London), 13, 530 (1972).

10. M.A. Abed and A. Saxena, Colloids and Surfaces A: Physiochemical and Engineering Aspects, No. 181, 233 (2004).

11. A. Khan, G.F. Durrani, M. Usman and W.H. Siddiq, J. Chem. Soc. Pak., 31, 4 (2009).

12. O.E. Ohrn, J. Polym. Sci., 17, 137 (1955).

13. S. Soni, V.N. Sastry, K.A. Patra, V.J. Joshi and S.P. Goyal, J. Phys. Chem. B, 106, 13069 (2002).

14. S. Soni, V.N. Sastry, K.A. Patra, V.J. Joshi and S.P. Goyal, J. Phys. Chem. B, 106, 2606 (2002).

15. A. Khan, G.F. Durrani, M. Usman and W.H. Siddiq, J. Chem. Soc. Pak., 31, 731 (2009).

16. M.K. Baloch, A. Rauf, F. Ahmad and G.F. Durani, J. Appl. Polym. Sci., 114, 1444 (2009). 